\title{
EFFECT OF GRAIN SIZE, TEMPERATURE AND CATALYST AMOUNT ON PYROLYSIS PRODUCTS OF SPIRULINA PLATENSIS RESIDUE (SPR)
}

\author{
Siti Jamilatun ${ }^{1}$, Budhijanto ${ }^{2}$, Rochmadi ${ }^{2}$, Avido Yuliestyan ${ }^{3}$, Arief Budiman ${ }^{1 *}$, \\ ${ }^{1}$ Department of Chemical Engineering, Faculty of Industrial Technology, Universitas Ahmad Dahlan, \\ Jalan Kapas 9, Yogyakarta 55166, Indonesia \\ ${ }^{2}$ Department of Chemical Engineering, Faculty of Engineering, Universitas Gadjah Mada, Jalan \\ Grafika 2, Yogyakarta 55284, Indonesia \\ ${ }^{3}$ Department of Chemical Engineering, Faculty of Industrial Technology, Universitas Pembangunan \\ Nasional "Veteran” Yogyakarta, Jalan SWK 104, Yogyakarta 55283, Indonesia.
}

(Received: July 2018 / Revised: October 2018 / Accepted: April 2019)

\begin{abstract}
Spirulina platensis microalgae is one of the feedstocks used in the production of the third generation of biofuel. The extraction of its lipid for biodiesel leaves behind a residue, which can be treated by pyrolysis to create certain other value-added products. This paper discusses the effects of Spirulina platensis residue (SPR) with respect to grain size $(0.105,0.149$ and 0.177 $\mathrm{mm})$, temperature $\left(300\right.$ to $\left.600^{\circ} \mathrm{C}\right)$ and amount of catalyst $(0,10,20$ and $40 \mathrm{wt} . \%)$ on the characteristics of products (bio-oil, water phase, char and gas) obtained from pyrolysis in a fixedbed reactor. The results of the study show that the higher the pyrolysis temperature, the higher the conversion. For the bio-oil product, the optimum temperature is $500^{\circ} \mathrm{C}$, which produces a peak yield of $35.99 \mathrm{wt} . \%$. The larger the grain size, the lower the bio-oil yield, gas water and gas, for all of the tested temperatures $\left(300-600^{\circ} \mathrm{C}\right)$. The amount of catalyst and the pyrolysis temperature greatly influence the quality of bio-oil products, grouping them into the fractions of LPG $(\mathrm{C} \leq 4)$, gasoline (C5-C11), biodiesel (C12-C18) and heavy naphtha (C $\geq 19)$. The tendency for LPG-Gasoline formation at optimum conditions, considering the use of a $10 \mathrm{wt}$ \% catalyst at a temperature of $400-500^{\circ} \mathrm{C}$, was reported.
\end{abstract}

Keywords: Alumina silica; Bio-oil pyrolysis; Fixed-bed; Spirulina platensis residue

\section{INTRODUCTION}

The massive exploitation of non-renewable natural resources may pose a threat to lives in the future arising from an increase in associated health issues and the greater risk of environmental damage that stems from the lower energy reserves and greater release of emissions during their processing (Anggorowati et al., 2018; Setyawan et al., 2018). There is thus an urgent need to replace non-renewable energy sources with renewable ones. Biomass is one of the most potent renewable energy sources, with its development having now led to the third generation of biofuel (Purwanto et al., 2015; Supramono et al., 2015; Jamilatun et al., 2017a; Kusrini et al., 2018a).

The first-generation biofuels (Fatty Acid Methyl Esters (FAME) or biodiesel, corn ethanol and sugar alcohol) were produced from lignocellulosic sources in the form of vegetable oils, corn, sugar and others. Although safer from an environmental perspective, a negative impact on food security may have arisen due to competition with food for consumption (Naik et al., 2010; Maity

\footnotetext{
*Corresponding author's email: abudiman@ugm.ac.id, Tel. +62-274-902170, Fax.+62-274-902170 Permalink/DOI: https://dx.doi.org/10.14716/ijtech.v10i3.2918
} 
et al., 2014). Different from their predecessors, second-generation biofuels (hydrotreating oil, bio-oil, ethanol from lignocellulose, butanol and alcohol mixtures) were developed to address the aforementioned issue on biofuel production by using non-food lignocellulosic sources such as agricultural residues, forests, grasses, aquatic biomass, etc. Despite not competing for resources with food production as they are derived from renewable resources, and with lower costs of production, the raw material resources used in the first and second generations did require extensive land; hence, biofuel production per area is relatively low (Pradana et al., 2017a; Sudibyo et al., 2017). To that end, microalgae, which requires less land to produce, offers the potential to be developed as a resource for use in the third generation of biofuels (Jamilatun et al., 2017b; Pradana et al., 2017b). Microalgae can be converted into biofuels through either a thermal or biological process. Pyrolysis technology can be utilized to process microalgae into third-generation biofuels (Yuliansyah et al., 2015). The initial process begins with the extraction of Spirulina platensis microalgae to leave behind a solid residue known as Spirulina platensis residue (SPR). The process of pyrolysis can then be applied to convert this low-value material into highly valuable fuel products and chemicals.

Microalgae pyrolysis is influenced by many parameters, such as the biomass type, temperature, heating rate, residence time, size and shape, catalyst, etc., as partly reported by Zheng et al. (2018). Temperature is the most significant of these operating parameters and has a tremendous effect on the product composition; indeed, pyrolysis is generally carried out at a temperature range of $400-600^{\circ} \mathrm{C}$ (Kusrini et al., 2018b). Within this temperature range, the liquid phase is mostly produced, which accounts for around 60-70 of the wt.\%. However, further increasing the temperature beyond its optimum will lead to secondary cracking, whereby tar from the primary cracking product will be converted into gas and char. The effect of secondary cracking is a decline in bio-oil products and an increase in gas products (Dickerson \& Soria, 2013).

In a fast pyrolysis process, it is generally assumed that the increase in grain size produces a greater temperature gradient in the particles. At any given time, the core temperature is lower than that of the surface of the biomass particles. This can lead to an increase in charcoal, while the amounts of gas and bio-oil decrease. Small particles have an adequate surface area via which to interact with pyrolysis media to form volatile products, thus enabling them to leave the biomass matrix without experiencing any secondary reactions. However, in the case of slow pyrolysis, particle size shows a less significant effect on product yield (Yang et al., 2019).

The presence of an additional catalyst significantly affects the product yield in catalytic pyrolysis. The gas yield increases and charcoal is initially produced, the amount of which is subsequently increased with the addition of the catalyst. In addition, charcoal yield reaches a minimum of 9 wt.\% when the mass ratio of the raw material/catalyst is $1: 3$. The addition of further catalyst increases the catalytic cracking rate, thereby aiding in the formation of gas compounds. Furthermore, the oil yield decreases as the loading of the catalyst increases. This phenomenon occurs due to secondary steam cracks (Qi et al., 2018).

This paper aims to characterize the SPR pyrolysis products (bio-oil, water phase, char and gas) in fixed-bed reactors with various temperatures, SPR grain sizes and number of catalysts used. The ultimate, proximate and calorific values of the raw materials in the form of SPR are analyzed, while the components of the alumina-silica catalyst are analyzed by SEM-EDX (Scanning Electron Microscopy Energy-Dispersive X-Ray Analysis). The pyrolysis products in the form of bio-oil will be analyzed with GC-MS (Gas Chromatography-Mass Spectrometry), with the components then grouped into the fractions of LPG $(\mathrm{C} \leq 4)$, gasoline $(\mathrm{C} 5-\mathrm{C} 11)$, biodiesel $(\mathrm{C} 12-$ $\mathrm{C} 18)$ and heavy naphtha $(\mathrm{C} \geq 19)$. 


\section{METHODS}

\subsection{Materials}

Spirulina platensis residue (SPR) was obtained from solid residues of Spirulina platensis extraction. Dry SPR was sieved and separated by grain size, i.e. $0.105,0.149$ and $0.177 \mathrm{~mm}$, corresponding to the sizes required to pass through a 120, 100 and 80 mesh, respectively. SPR has certain characteristics relating to its components as obtained from: (a) ultimate analysis, where $\mathrm{C}, \mathrm{H}, \mathrm{O}, \mathrm{N}$ and $\mathrm{S}$ are 41.36, 6.60, 35.33, 7.17 and 0.55 wt.\%, respectively; and (b) proximate analysis, where carbohydrate, protein and lipids are 25.59, 49.60 and 0.09 wt.\%, respectively (Jamilatun et al., 2017a). The aforementioned data on the characteristics were obtained from tests conducted by TEKMIRA, Bandung, Indonesia.

The catalyst used for this study was silica-alumina $\left(\mathrm{SiO}_{2} / \mathrm{Al}_{2} \mathrm{O}_{3}\right)$ obtained from PTPN V, Sei Galuh, Riau Indonesia. Analysis, performed by LPPT UGM, revealed the Si/Al catalyst to contain $\mathrm{C}, \mathrm{O}, \mathrm{Al}$ and $\mathrm{Si}$ in the respective proportions of 8.41, 55.78, 24.64 and $11.17 \mathrm{wt} \%$. In addition, the catalyst pore surface area, diameter and average pore volume were $240.553 \mathrm{~m}^{2} / \mathrm{g}$ surface area, $3.3 \mathrm{~nm}$ and $0.199 \mathrm{~cm}^{3} / \mathrm{g}$ total pore volume, respectively.

\subsection{Methods}

The cylinder reactor consists of upper and lower parts in which to place the SPR and catalyst, respectively. A condenser was also installed for the purpose of liquefying volatile matter. This reactor has ID $\times \mathrm{L}$ dimensions of $40 \mathrm{~mm} \times 60 \mathrm{~cm}$. Pyrolysis was run at temperatures between 300 and $600^{\circ} \mathrm{C}$ at a heating rate of $20-40^{\circ} \mathrm{C} / \mathrm{min}$. A schematic image of the fixed-bed reactor is shown in Figure 1 (Jamilatun et al., 2017a).

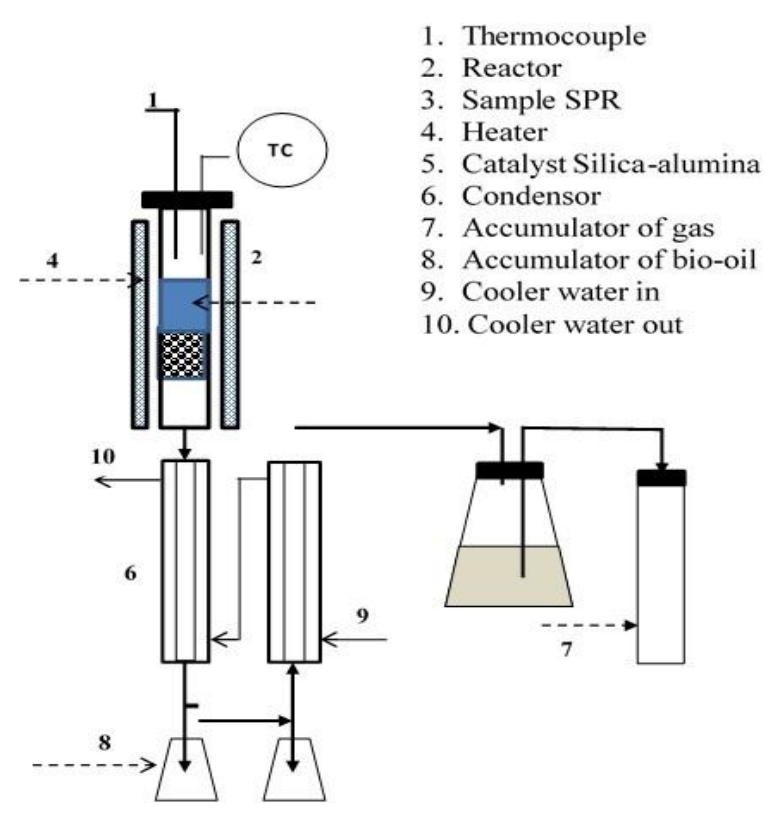

Figure 1 Schematic diagram of the fixed-bed reactor

Fifty grams of SPR was inserted into the upper part of the reactor, which was then tightly closed. The amount of catalyst, which was contained in the lower part of the reactor, varied with reference to the cases of 10,20 and $40 \mathrm{wt} . \%$. Heating began from a temperature of $30^{\circ} \mathrm{C}$ and was increased to the desired temperature $\left(300-600^{\circ} \mathrm{C}\right)$ at a rate of $3-35^{\circ} \mathrm{C} /$ minute. Once the desired temperature was reached, it was then maintained for a period of around 1 hour to ensure that the pyrolysis ran perfectly. The yields of bio-oil product, water phase, char and gas were calculated using the following equations, respectively (Jamilatun et al., 2017a). 


$$
\begin{aligned}
& Y_{L}=\left(W_{L} / W_{M}\right) \times 100 \% \\
& Y_{B o}=\left(W_{B o} / W_{M}\right) \times 100 \% \\
& Y_{W p}=\left(W_{A} / W_{M}\right) \times 100 \%=Y_{L}-Y_{B o} \\
& Y_{C}=\left(W_{C} / W_{M}\right) \times 100 \% \\
& Y_{G}=1-\left(Y_{L}+Y_{C}\right)
\end{aligned}
$$

SPR $(X)$ pyrolysis conversion can be determined using the following equation.

$$
X=\frac{W_{B o}+W_{A}+W_{G}}{W_{M}} \times 100 \%
$$

In this case, $W_{M}, W_{L}, W_{B o}, W_{W p}, W_{C}$ and $W_{G}$ represent the weight of SPR, liquid, bio-oil, water phase, char and gas, respectively. While $Y_{L}, Y_{B o}, Y_{W p}, Y_{C}$ and $Y_{G}$ represent the yields of liquid, bio-oil, water phase, char and gas

\section{RESULTS AND DISCUSSION}

\subsection{Characterization of Pyrolysis Products with Various SPR Grain Sizes and Temperatures}

The yield results for pyrolysis products with varying sizes of SPR $(0.105,0.149$ and $0.177 \mathrm{~mm})$ and pyrolysis temperatures at a heating rate of $5-35^{\circ} \mathrm{C} /$ minute can be seen in Figure 2.

Figure $2 \mathrm{a}$ shows that the higher the pyrolysis temperature, the higher the bio-oil yield. The optimum temperature is $500^{\circ} \mathrm{C}$. Any further increase in the temperature produces a lower bio-oil yield as a result of secondary cracking. This type of cracking results in the tar that was initially formed in the primary cracking being turned into gas and char. The evidence for this can be seen in Figures $2 b-2 d$, where an increase in temperature generates a slightly higher water phase product, a much greater amount of gas at the temperature of $500^{\circ} \mathrm{C}$ and a sharply declining amount of char. In addition, the SPR grain size also affects the product yield. At each corresponding temperature, the larger the grain size, the smaller the yield of almost all products, except for char.

At $500^{\circ} \mathrm{C}$, the grain size increased from 0.105 to $0.177 \mathrm{~mm}$, while the bio-oil yield was observed to decrease from 35.99 to $32.86 \mathrm{wt}$.\%. In contrast, the percentage yield of char rose from 23.10 to $34.02 \mathrm{wt} \%$. Meanwhile, the others remained the same at all grain sizes, thus confirming the earlier study by $\mathrm{Hu}$ (2013). It was reported that the effect of grain size at a certain temperature $\left(500^{\circ} \mathrm{C}\right)$ will be stronger for bio-oil and char. Explaining this further, the increase in grain size produced a sharp decline in the bio-oil yield and a sharp rise in the char yield, whilst the gas and water phase yields remained fairly stable at all grain sizes.

It is generally assumed that an increase in grain size produces a greater temperature gradient in particles, so that at any given time the core temperature is lower than that at the surface of the biomass particles. Furthermore, it can lead to an increase in charcoal, while there are falls in the yield of gas and bio-oil. Small particles have a sufficient surface area to interact with pyrolysis media to form volatile products, thus leaving the biomass matrix without experiencing secondary reactions (Kan et al., 2016). Jalan and Srivastava (1999) stated that in the case of slow pyrolysis, particle size displayed a less significant effect on product yield. SPR pyrolysis conversion is calculated by summing the weight of the bio-oil, water phase and gas yields divided by the initial weight (Equation 6). An explanation of the increase in pyrolysis conversion at temperatures of $300-600^{\circ} \mathrm{C}$ with variations in grain size can be seen in Figure 3. 

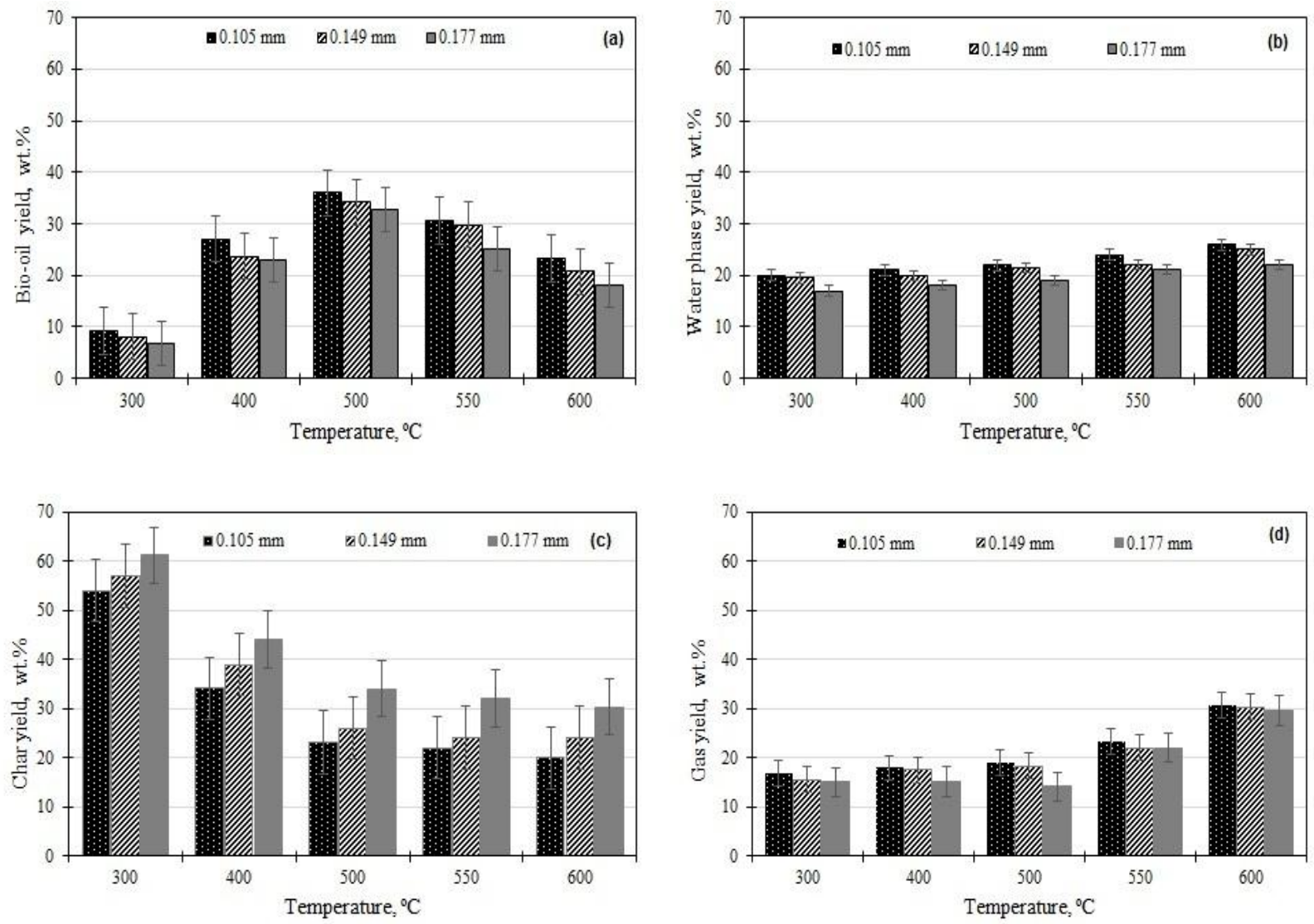

Figure 2 Effect of pyrolysis temperature and SPR grain size on yield of products: (a) yield of bio-oil; (b) yield of water phase; (c) yield of char; (d) yield of gas

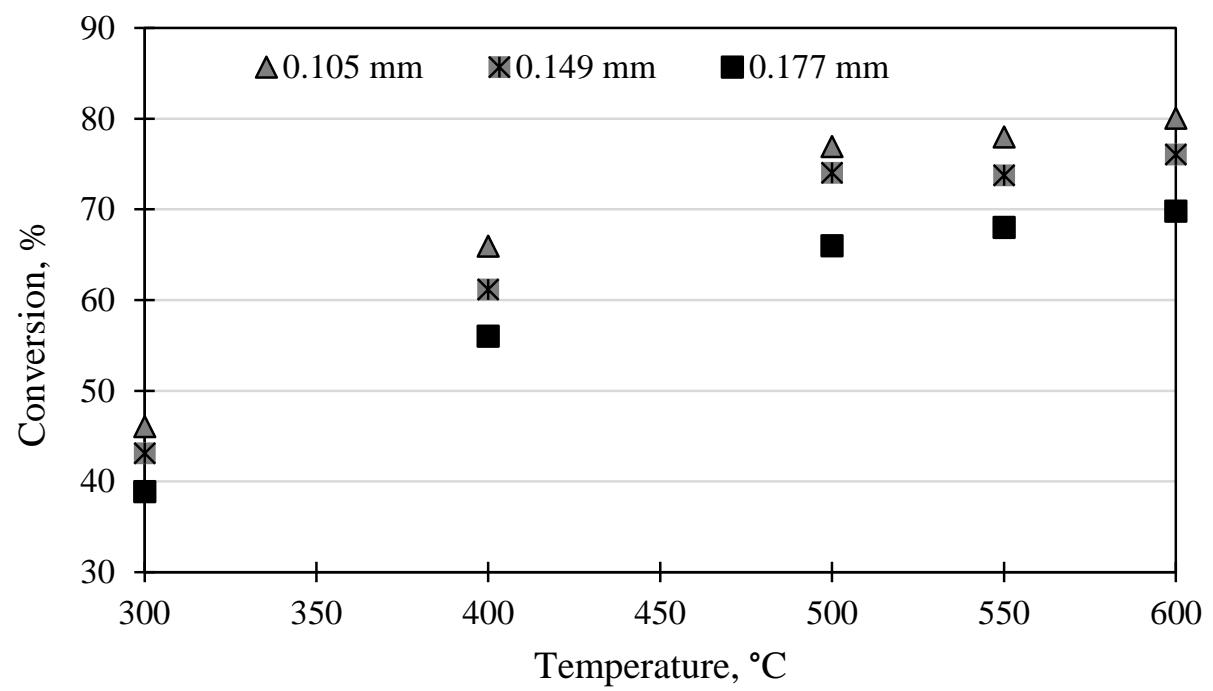

Figure 3 Relationship between grain size and conversion at various pyrolysis temperatures

Along with the increase in pyrolysis temperature and the smaller SPR grain size, the thermal decomposition is more effective; thus, the SPR weight decreases, causing the conversion to increase. The increased liquid and gas products indicate that the speed of the decomposition reaction increases in line with the increasing temperature and smaller grain size (Kan et al., 2016). Considering the low thermal conductivity of biomass, the biomass particles that provide rapid 
heating to achieve a high bio-oil yield should be very small. Although a high heating rate can be achieved in a pyrolysis reactor, the low thermal conductivity of biomass inhibits temperature gradients across particles. Jalan and Srivastava (1999) observed that the pyrolysis process was controlled by primary pyrolysis reactions and external heat transfer for small particle sizes $(<1$ $\mathrm{mm})$, while for large particle sizes $(>1 \mathrm{~mm})$ the process was controlled by heat transfer in conjunction with both primary and secondary pyrolysis.

\subsection{Characterization of Pyrolysis Products with Varying Amounts of Catalyst}

Figure 4 presents the pyrolysis product yields plotted on the y-axis against the catalyst percentage (0-40 wt.\%). The pyrolysis process was initially conducted at four different temperatures of 400 , 500,550 and $600^{\circ} \mathrm{C}$ using the fixed variable of grain size set to $0.105 \mathrm{~mm}$.
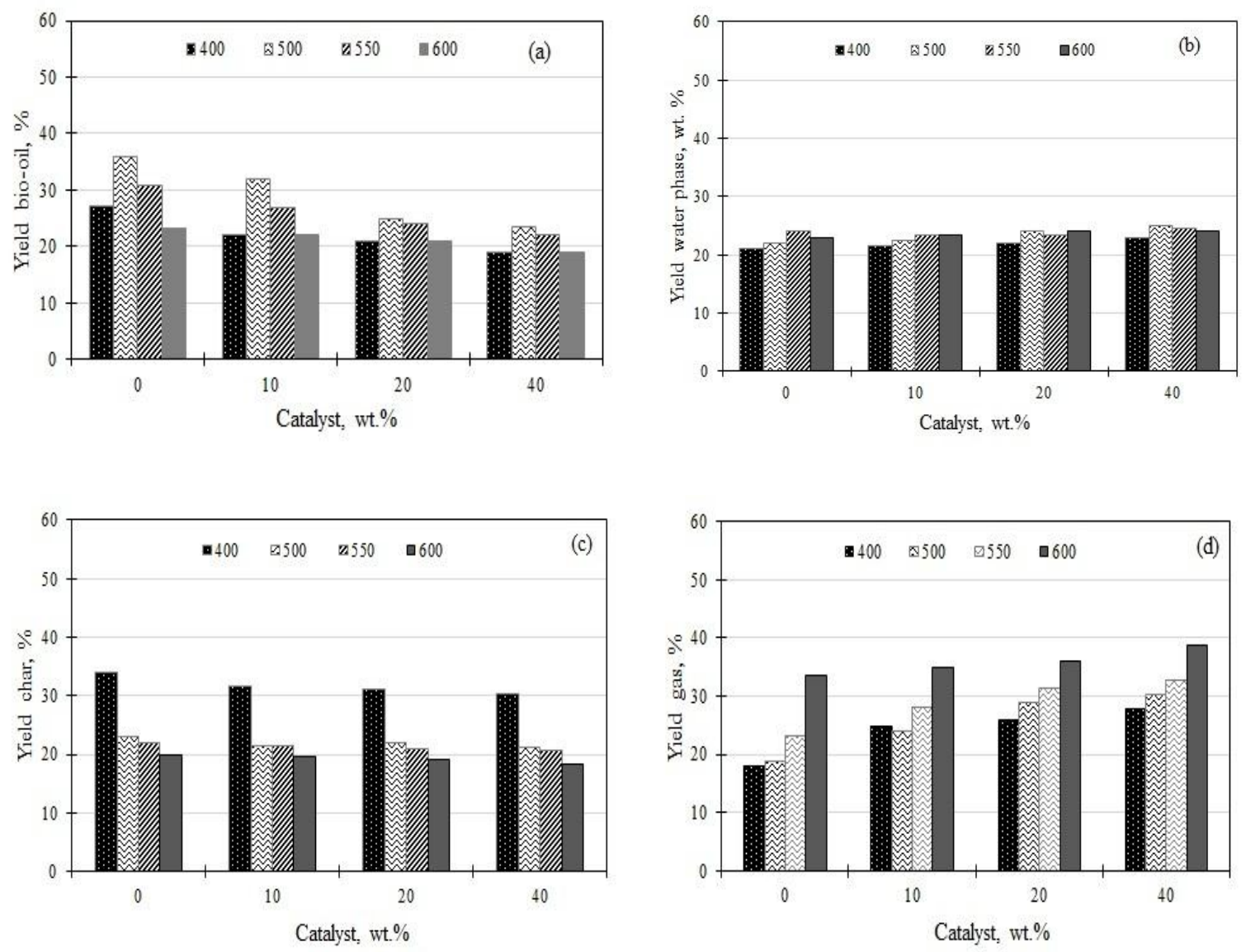

Figure 4 The effect of using catalysts on product composition in pyrolysis with an SPR grain size of $0.105 \mathrm{~mm}$ : (a) yield of bio-oil; (b) yield of water phase; (c) yield of char; (d) gas yield

From Figure 4a, for instance, the yield of bio-oil products at $500^{\circ} \mathrm{C}$ can be seen in the following case order, starting with the largest: without catalyst $(35.99 \mathrm{wt} . \%)>$ with a catalyst of $10 \mathrm{wt} . \%$ $(32.00 \mathrm{wt} . \%)>20 \mathrm{wt} . \%(25.00 \mathrm{wt} . \%)>40 \mathrm{wt} . \%$ (23.50 wt.\%). Thus, an increase in the number of catalysts will eventually reduce the yield of bio-oil for all pyrolysis temperatures $\left(400-600^{\circ} \mathrm{C}\right)$.

As presented in Figure $4 \mathrm{~b}$, the ranges for the water phase with the use of catalysts from 0 to $40 \%$ are from about $22.00 \pm 1.00 \%$ to $23.50 \pm 0.50 \%$ in a linear increasing order. This means that an increase in the amount of catalysts used creates a tendency for the yield of the water phase to increase. This finding is aligned with that from a study by Aysu (2015), where an increasing amount of catalysts led to deoxygenation (dehydration and hydrodeoxygenation) reactions occurring more quickly and effectively, thus generating increased water formation. 
From Figures $4 \mathrm{~d}$ and $4 \mathrm{e}$, it can be explained that there is a decrease in the char yield and a sharp rise in the gas yield for all temperatures $\left(400-600^{\circ} \mathrm{C}\right)$ in line with an increase in the number of catalysts. An increase in the number of catalysts will lead to an increase in conversion, where the number of non-condensable and condensable gas products increases, causing the char yield to decrease. The increase in gas yield (non-condensable gas) is caused by decarbonylation and decarboxylation reactions, while the increase in water is due to hydrodeoxygenation and hydrogenation reactions. Condensable gas (bio-oil) is influenced by all reactions, including cracking, hydrocracking, deamination, decarbonylation, decarboxylation, hydrodeoxygenation, hydrogenation and cyclisation (Dickerson \& Soria, 2013; Qi et al., 2018).

Figure 5 shows the relationship between the number of catalysts and its conversion within the temperature range of $400-600^{\circ} \mathrm{C}$. It can be seen that an increase in temperature from 400 to $600^{\circ} \mathrm{C}$ leads to an approximate $10 \%$ increase in the amount of converted product, from \pm 70 to $80 \%$, regardless of the division into bio-oil, water phase, char and gas, as previously shown in Figure 4. In addition, the influence of the number of catalysts on the conversion is more pronounced at a lower temperature $\left(\right.$ at $400^{\circ} \mathrm{C}$ ) than at a higher temperature. Interestingly, the catalytic pyrolysis process may not significantly influence the conversion, but instead tends to markedly affect the desired composition percentage. (Aysu, 2015).

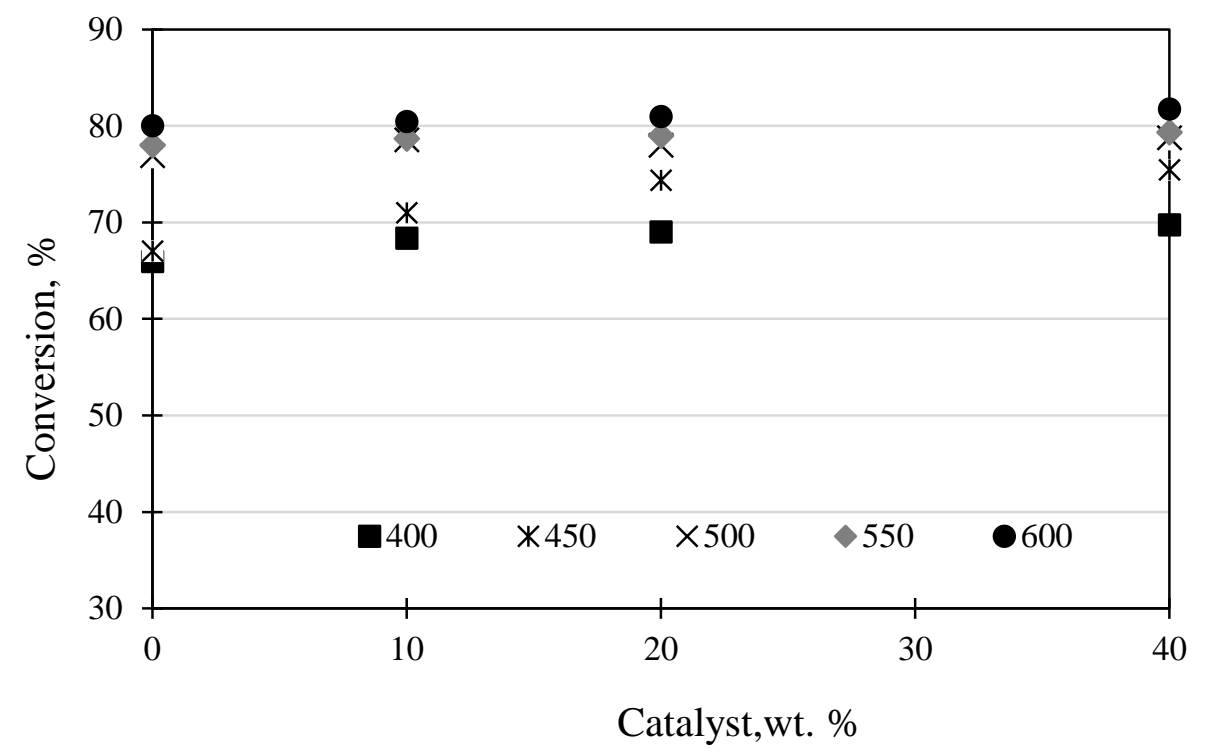

Figure 5 Relationship between the number of catalysts and conversion at various pyrolysis temperatures with an SPR grain size of $0.105 \mathrm{~mm}$

\subsection{Grouping of Bio-oil Fraction based on the Amount of C Atoms}

The grouping into LPG, gasoline, diesel and heavy naphtha fractions is based merely on the number of $\mathrm{C}$ atoms available, as observed in the compounds contained in bio-oil, without considering the groups of alcohol, aldehydes, ketones, acids, nitrogenated or other compounds. From the results of GC-MS, more than 100 bio-oil constituents are obtained. The grouping of bio-oil products into the fractions of LPG $(\mathrm{C} \leq 4)$, gasoline $(\mathrm{C} 5-\mathrm{C} 11)$, diesel $(\mathrm{C} 12-\mathrm{C} 18)$ and heavy naphtha $(C \geq 19)$ was performed by categorizing the number of $C$ atoms in bio-oil constituent compounds. The grouping of the results into fractions at $400,500,550$ and $600^{\circ} \mathrm{C}$ pyrolysis temperatures can be observed in Table 1. From the table, it can be seen that LPG products highly dominate the products in pyrolysis with or without catalysts for all temperatures tested. It can be explained that by employing the pyrolysis process, the complex compounds contained in carbohydrates and proteins can be decomposed into smaller-size condensable compounds. These condensed liquids are mainly composed of compounds having $\mathrm{C} \leq 4$. 
By using the catalyst, we can see that the fractions other than LPG (gasoline, diesel and heavy naphtha) begin to grow, despite LPG remaining as the dominant fraction. From the results of GCMS, it can be seen that the LPG fraction comprises a compound with $C \leq 4$, likely by a methanol component, which has high potential as a product for use as a fuel or additive (Jamilatun et al., 2017a; Sun et al., 2019). The use of catalysts in pyrolysis is aimed at improving the quality of bio-oil by increasing the aromatic and short chain compounds $\mathrm{C} \leq 4 \mathrm{C}$ and $\mathrm{C} 5-\mathrm{C} 11$ through cracking and deoxygenation reactions. The use of a catalyst significantly affects the composition of the product and increases conversion with increasing temperatures (Aysu, 2015). From catalytic and non-catalytic pyrolysis, it is expected that fuel with a fraction between LPG and gasoline will be produced. This study derived the optimum condition, with the best results obtained with the use of $10 \mathrm{wt} . \%$ catalyst at a temperature of $400-500^{\circ} \mathrm{C}$.

Table 1 Bio-oil fraction without and with catalyst

\begin{tabular}{lrrrr}
\hline \multirow{2}{*}{ Bio-oil fraction } & \multicolumn{4}{c}{ Temperature, ${ }^{\circ} \mathrm{C}$} \\
\cline { 2 - 5 } & \multicolumn{1}{c}{500} & \multicolumn{1}{c}{500} & \multicolumn{1}{c}{600} \\
\hline Without catalyst & & & & \\
LPG & 96.30 & 80.16 & 85.50 & 98.32 \\
Gasoline & 1.73 & 4.14 & 9.19 & 0.33 \\
Diesel & 1.91 & 12.45 & 4.97 & 0.00 \\
Heavy naphtha & 0.09 & 3.25 & 0.33 & 1.36 \\
Catalyst, 10 wt.\% & & & & \\
LPG & 45.48 & 55.31 & 81.28 & 66.23 \\
Gasoline & 35.70 & 28.95 & 6.17 & 23.54 \\
Diesel & 14.73 & 12.92 & 9.28 & 9.59 \\
Heavy naphtha & 3.10 & 2.82 & 3.27 & 14.48 \\
Catalyst, 20 wt.\% & & & & \\
LPG & 73.03 & 69.64 & 86.36 & 22.58 \\
Gasoline & 5.03 & 18.91 & 4.66 & 58.70 \\
Diesel & 24.19 & 10.62 & 7.47 & 15.88 \\
Heavy naphtha & 2.40 & 0.84 & 1.51 & 2.87 \\
Catalyst, 40 wt.\% & & & & \\
LPG & 69.23 & 78.97 & 78.54 & 81.23 \\
Gasoline & 7.10 & 3.36 & 5.71 & 3.04 \\
Diesel & 8.39 & 14.36 & 12.50 & 13.83 \\
Heavy naphtha & 1.14 & 3.31 & 13.83 & 1.95 \\
\hline
\end{tabular}

\section{CONCLUSION}

As a raw material source in the production of third-generation biofuel, Spirulina platensis residue offers the potential to be developed on a large scale due to its ease of cultivation, simple processing pyrolysis technology and low cost. Temperature and the grain size of SPR microalgae affect the composition of the product. Bio-oil yield will increase from 9.22 to $33.99 \mathrm{wt} \%$ at a temperature of $300-500^{\circ} \mathrm{C}$, then fall to $23.34 \mathrm{wt} . \%$ at $600^{\circ} \mathrm{C}$ with an SPR grain size of at least $0.105 \mathrm{~mm}$. This positive-peak curvature trend also applies to the sizes of 0.149 and $0.177 \mathrm{~mm}$. However, the larger the grain size, the lower the bio-oil yield. An increase in grain size seems to produce a fall in the water phase, gas and its total conversion, whereas the opposite is shown for the yield of char. This applies to all temperatures $\left(300-600^{\circ} \mathrm{C}\right)$.

The use of a catalyst affects the composition of the product. A greater amount of catalysts (0-40 wt.\%) appears likely to result in a lower yield of bio-oil and char, with greater amounts of converted product obtained in the gas phase and fairly constant amounts in the water phase. 
Based on the grouping of the number of $\mathrm{C}$ atoms in the bio-oil constituent, the dominant fraction is the LPG-Gasoline fraction, with methanol being the most highly available component. In the optimum condition at temperatures of $400-500^{\circ} \mathrm{C}$, pyrolysis with the use of $10 \mathrm{wt} \%$ catalyst produced about $45.48-55.31 \mathrm{wt} . \%$ of LPG fraction and 35.70-28.95 wt.\% of gasoline fraction.

\section{ACKNOWLEDGEMENT}

The author is very grateful for the funding support from the Ministry of Research, Technology, and Higher Education, Republic of Indonesia. We also gratefully acknowledge the funding from USAID through the SHERA program - Centre for Development of Sustainable Region (CDSR) (077/Kontrak/TA/03/2018).

\section{REFERENCES}

Aysu, T., 2015. Catalytic Pyrolysis of Alcea Pallida Stems in a Fixed-bed Reactor for Production of Liquid Bio-fuels. Bioresource Technology, Volume 191, pp. 253-262

Anggorowati, H., Jamilatun, S., Rochim, B., Cahyono, Budiman, A., 2018. Effect of Hydrochloric Acid Concentration on the Conversion of Sugarcane Bagasse to Levulinic Acid. In: IOP Conference Series: Materials Science and Engineering. 299, 012092

Dickerson, T., Soria, J., 2013. Catalytic Fast Pyrolysis: A Review. Energy, Volume 6(1), pp. 514538

Hu, Z., Zheng, Y., Yan, F., Xiao, B., Liu, S., 2013. Bio-oil Production through Pyrolysis of Blue-green Algae Blooms (BGAB): Product Distribution and Bio-oil Characterization. Energy, Volume 52, pp. 119-125

Jalan, R.K., Srivastava, V.K., 1999. Studies on Pyrolysis of a Single Biomass Cylindrical Pellet Kinetic and Heat Transfer Effects. Energy Conversion and Management, Volume 40(5), pp. 467-494

Jamilatun, S., Budiman, A., Budhijanto, B., Rochmadi, R., 2017a. Non-catalytic Slow Pyrolysis of Spirulina Platensis Residue for Production of Liquid Biofuel. International Journal of Renewable Energy Research, Volume 7(4), pp. 1901-1908

Jamilatun, S., Budhijanto, B., Rochmadi, R. Budiman, A. 2017b. Thermal Decomposition and Kinetic Studies of Pyrolysis of Spirulina Platensis Residue. International Journal of Renewable Energy Development, Volume 6(3), pp. 193-201

Kan, T., Strezov, V., Evans, T.J., 2016. Lignocellulosic Biomass Pyrolysis: A Review of Product Properties and Effects of Pyrolysis Parameters. Renewable and Sustainable Energy Reviews, Volume 57, pp. 1126-1140

Kusrini, K., Wicaksono, W., Gunawan, C., Daud, N.Z.A., Usman, A., 2018a. Kinetics, Mechanism, and Thermodynamics of Lanthanum Adsorption on Pectin Extracted from Durian Rind. Journal of Environmental Chemical Engineering, Volume 6(5), pp. 6580-6588

Kusrini, K., Supramono, D., Degirmenci, V., Pranata, S., Bawono, A.A., Ani F.N., 2018b. Improving the Quality of Pyrolysis Oil from Co-firing High-density Polyethylene Plastic Waste and Palm Empty Fruit Bunches. International Journal of Technology, Volume 9(7), pp. 1498-1508

Maity, J.P., Bundschuh, J., Chen, C-Y., Bhattacharya, P., 2014. Microalgae for Third Generation Biofuel Production, Mitigation of Greenhouse Gas Emissions and Wastewater Treatment: Present and Future Perspectives: A Mini Review. Energy, Volume 78, pp. 104-113

Naik, S.N., Goud, V.V, Rout, P.K., Dalai, A.K., 2010. Production of First and Second Generation Biofuels: A Comprehensive Review. Renewable and Sustainable Energy Reviews, Volume 14(2), pp. 578-597 
Purwanto, W.W., Supramono, D., Muthia, R., Firdaus, M.F., 2015. Effect of Biomass Types on Bio-oil Characteristics in a Catalytic Fast Pyrolysis Process With a Ni/ZSM-5 Catalyst, International Journal of Technology, Volume 7, pp. 1069-1075

Pradana, Y.S., Hidayat, A., Prasetya, A., Budiman, A., 2017a. Biodiesel Production in a Reactive Distillation Column Catalyzed by Heterogeneous Potassium Catalyst. Energy Procedia, Volume 143, pp. 742-747

Pradana, Y.S., Kusumastuti, Y., Rahma, F.N., Effendy, N., 2017b. Chitosan FlocculationSedimentation for Harvesting Selected Microalgae Species Grown in Monoculture and Mixed Cultures. Chemical Engineering Transactions, Volume 56, pp. 1549-1554

Qi, P., Changa, G., Wang, H., Zhang, X., Guo, Q., 2018. Production of Aromatic Hydrocarbons by Catalytic Co-pyrolysis of Microalgae and Polypropylene using HZSM-5. Journal of Analytical and Applied Pyrolysis, Volume 136, pp. 178-185

Supramono, D., Devina, Y.M., Tristantini, D., 2015. Effect of Heating Rate of Torrefaction of Sugarcane Bagasse on its Physical Characteristics. International Journal of Technology, Volume 6(7), pp. 1084-1093

Sudibyo, H., Purwanti, Y., Pradana, Y.S., Samudra, T.T., Budiman, A., Suyono, E.A., 2017. Modification of Growth Medium of Mixed-culture Species of Microalgae Isolated from Southern Java Coastal Region In: MATEC Web of Conference, Volume 154

Setyawan, M., Budiman, A., Mulyono, P., Sutijan, 2018. Optimum Extraction of Algae-oil from Microalgae using Hydrodynamic Cavitation. International Journal of Renewable Energy Research, Volume 8(1), pp. 451-458

Sun, Y., Zhou, W., Wangd, H., Guo, G., Su, Z., Pua, Y., 2018. Antialgal Compounds with Antialgal Activity Against the Common Red Tide Microalgae from a Green Algae Ulva Pertusa, Ecotoxicol Environ. Safe, Volume 157, pp. 61-66

Yuliansyah, A.T., Prasetya, A., Ramadhan, M.A.A., Laksono, R., 2015. Pyrolysis of Plastic Waste to Produce Pyrolytic Oil as an Alternative Fuel. International Journal of Technology, Volume 6(7), pp. 1076-1083

Yang, C., Li, R., Zhang, B., Qiu, Q., Wang, B., Yang, H., Ding, Y., Wang, C., 2019. Pyrolysis of Microalgae: A Critical Review. Fuel Processing Technology, Volume 186, pp. 53-72

Zheng, Y., Tao, L., Yang, X., Huang, Y., Liu, C., Zheng, Z., 2018. Study of the Thermal Behavior, Kinetics, and Product Characterization of Biomass and Low-density Polyethylene Co-pyrolysis by Thermogravimetric Analysis and Pyrolysis-GC/MS. Journal of Analytical and Applied Pyrolysis, Volume 133, pp. 185-197 